\title{
Análise bioética do Código de Ética Odontológica brasileiro
}

\author{
Bioethical analysis of the Brazilian Dentistry Code of Ethics
}

MoniquePyrrho ${ }^{1}$

M auro $M$ achado do Prado ${ }^{1}$

Jorge Cordón ${ }^{1}$

Volnei Garrafa ${ }^{1}$

${ }^{1}$ Cátedra Unesco de

Bioética, Universidade de

Brasília. Caixa Postal

04451. 70904-970.

Brasília, DF.

bioetica@unb.br
Abstract The Brazilian Dentistry Code of Ethics (DCE), Resolution CFO-71 from M ay 2006, is an instrument created to guide dentists' behavior in relation to the ethical aspects of professional practice. The purpose of the study is to analyze the above mentioned code comparing the deontological and bioethical focuses. In order to do so, an interpretative analysis of the code and of twelve selected texts was made. Six of the texts were about bioethics and six on deontology, and theanalysis was madethrough themethodological classification of the context units, textual paragraphs and items from the code in the following categories: the referentials of bioethical principlism - autonomy, beneficence, nonmaleficence and justice - , technical aspects and moral virtues related to the profession. Together the four principles represented $22.9 \%, 39.8 \%$ and $54.2 \%$ of the content of the DCE, of the deontological texts and of the bioethical texts respectively. In the DCE, $42 \%$ of the items referred to virtues, $40.2 \%$ were associated to technical aspects and just $22.9 \%$ referred to principles. The virtues related to the professionals and the technical aspects together amounted to $70.1 \%$ of the code. Instead of focusing on the patient as the subject of the process of oral health care, the DCE focuses on the professional, and it is predominantly turned to legalistic and corporate aspects.

Key words Dentistry code of ethics (DCE), D eontology, Bioethical principlism, Technical aspects, $M$ oral virtues
Resumo O Código de Ética Odontológica (CEO) brasileiro, Resolução CFO-71 de maio/2006, é um instrumento elaborado para orientar a conduta dos cirurgiões-dentistas sobre os aspectos éticos da prática profissional. 0 objetivo do estudo éanal isar O CEO comparando osenfoques deontológico ebioético. Para tal, realizou-se a análise interpretativa do CEO ede doze textos selecionados, seis sobre bi oética e seis sobre deontologia, por meio da classificação metodológica das unidades de contexto, parágrafos textuais e itens do código, nas seguintes categorias: os referenciais do principialismo bioético - autonomia, beneficência, não-mal eficência e justiça -, aspectos técnicos e virtudes morais relacionados à profissão. $0 \mathrm{~s}$ quatro princípios somados representaram $22,9 \%$, $39,8 \%$ e $54,2 \%$ do conteúdo do CEO, dostextos deontológi cos e dos bioéticos, respectivamente. No CEO, $42 \%$ dos itens referiam-se às virtudes, $40,2 \%$, a aspectos técnicos e apenas $22,9 \%$, aos princípios. As virtudes relacionadas aos profissionais e os aspectos técnicosjuntos representam 70,1\% do código. 0 CEO, em vez de centrar-se no paciente como sujeito do processo deatenção à saúde bucal, focaliza o profissional, sendo predominantemente voltado para aspectos legalistas e corporativistas.

Palavras-chave Código de Ética Odontológica (CEO), D eontologia, Bioética principialista, Aspectos técnicos, Virtudes morais 


\section{Introdução}

O profissional daárea de ciências da saúde, especialmente o odontólogo, tem, desde o início de sua formação, a atuação voltada principalmente para aspectos científicos e técnicos, relegando as questões atitudinais da profissão a segundo plano. Dentre muitas questõeséticas que resultam da prática odontológica, as principais remetem à relação profissional-paciente. Ainda que configurem questões eticamentepersistentes, os conflitos deinteressesurgidos nesta relação não possuem respostas definitivas.

Este tema é explorado como objeto de estudo por duas disciplinas. A bioética, uma disciplina autônoma fortemente embasada filosoficamente, propõe a análise e mediação dos conflitos gerados na aplicação das mais diversas áreas de conhecimento relacionadas às ciências biomédicas e da saúde. Possui um enfoque transdisciplinar, base ando-seno respeito ao pluralismo moral ena abordagem dos fatos a partir do paradigma da complexidade, entendendo que modelos e soluções padronizadas não têm êxito ante aos desafios impostos pela diversidade ${ }^{1,2}$.

E a ética profissional ou deontologia, queéhistoricamente relacionada ao exercício das profissões liberais, tem um conteúdo prescritivo e um corpo de normas ou deveres inerentes ao exercício profissional. 0 conjunto de prescrições baseadas na noção de respeito ao dever e nas obrigações identificadas socialmente à profissão apresenta-se tradicionalmente na forma de código de ética ${ }^{3}$.

O Código de Ética O dontológica $(C E O)^{4}$ vigente no Brasil, aprovado pela Resolução do Conselho Federal de Odontologia (CFO) 42 de 2003 e modificado pela Resolução CFO-71 demaio/20065, é uma construção da categoria profissional odontológica que busca orientar a conduta dos cirurgiões-dentistas no que diz respeito aos aspectos éticos de sua prática profissional. Fruto de uma construção histórica, teve como primeiro marco oficial o CEO de 1976, tendo sofrido diversas modificações até o presente momento. Os primeiros códigos foram elaborados por comissões constituídas para este fim. Posteriormente, sua elaboração passou a ser fruto de conferências constituídas por diversas entidades representativas, tornando-se mais próximo da realidade vivida pelos profissionais da área ${ }^{6}$. Desta forma, por meio da linguagem usada e da maneira como são abordadas as diferentes questões e descritas suas atividades, o código manifesta o tipo de reflexão ética a ser observado pel os cirurgiões-dentistas.

A análise de conteúdo de um código de ética, instrumento tão caro à deontologia, sob o prisma da bioética, oferece mais do que a possibilidade de comparar as disciplinas: permite uma interpretação mais abrangente das orientações que o código disponibiliza ea adequação de sua forma elinguagem aos fins a que se propõe.

Para este estudo, será utilizada como referência a teoria preferencial menteutilizada na bioética, o princi pialismo, embasada nos referenciais teóricos propostos por Beauchamp e Childress ${ }^{7}$ e seus princípios prima facie: autonomia, beneficência, não-mal eficência ejustiça.

Ao detectar as semelhanças e divergências entre a deontologia e a bioética, é possível delimitar quais vantagens e desvantagens que cada referencial possui e otimizar a contribuição que podem oferecer, gerando assim instrumentos mais adequados à atividade odontológica na sociedadecontemporânea, dinâmica tanto em seus aspectos científicos quanto morais.

0 objetivo deste estudo, portanto, é analisar o CEO vigente- um código de construção preferencialmente deontológico - sob a ótica da bioética, procurando detectar quais são as aproximações ou distanciamentos, semelhanças ou diferenças, vantagens ou desvantagens existentes entre os referenciais das bases deontológicas/ética profissional e aqueles preconizados pela bioética.

\section{Metodologia}

A primeira fase do projeto consistiu em uma leitura exploratória de diversos textos correlacionados ao tema, com o propósito de selecionar doze (12) textos brasileiros específicos, sendo seis (6) deles vinculados à bioética e outros seis (6) à deontologia/ ética profissional, além, naturalmente, do próprio CEO como documento referencial da pesquisa.

Selecionados os textos, seguiram-se os passos indicados pela metodologia de análise de conteúdo proposta por Bardin8: pré-análise, exploração do material, tratamento dos resultados, inferência einterpretação. Este método visa à análise do conteúdo do discurso por meio de inferências, avaliando objetivamente os dados frequenciais obtidos a partir do estudo textual baseado em um parâmetro analítico subjetivo.

O momento inicial do estudo consisteno quea autora chama de "leitura flutuante" ${ }^{8}$, uma leitura inicial de reconhecimento dos temas abordados pelos doze textos e pelo CEO. Posteriormente a esta fase, foram determinadas as categorias em que se subdividiram as unidades textuais. Para uma análise dos textos e do CEO sob uma ótica bioética, foram usadas seis categorias: os quatro princí- 
pios bioéticos - autonomia, beneficência, nãomaleficência e justiça - além do tema da "virtude" e a categoria que se chamou "técnica".

Segue-se a segunda fase, a "exploração do material", constituída por uma leitura pormenorizada decada texto, subdividindo as unidades de contexto - parágrafos nos textos sel ecionados e capítulos, seções, artigos e incisos no CEO - , de acordo com o corpo de seu texto e seu tema principal.

Visando à identificação dos referenciais bioéticos no conteúdo do CEO, o estabelecimento dos critérios de classificação iniciou-se com a determinação do referencial teórico principialista, devido a seu caráter hegemônico dentre as demais propostas teóricas bioéticas e a sua construção formal que facilita a classificação das unidades de contexto segundo as categorias estabelecidas.

A categorização das unidades textuais referentes aos princípios bioéticos respeitou um critério subjetivo de adequação segundo a conceituação de Beauchamp e Childress ${ }^{7}$. Um mesmo item ou unidade pode referir-se a mais de um princípio; portanto, é possível que seja incluído em mais de uma classificação. Isto justifica que, por vezes, a soma do total das unidades em cada categoria seja maior do que a soma das unidades em si.

Durante a leitura prévia à determinação das categorias que embasariam a classificação, ficou evidente que o conteúdo do CEO e também dos demais textos analisados não se restringia à referência dos quatro princípios bioéticos. Assim, foram estabelecidas outras duas categorias com 0 propósito de criar subsídios para adequar a classificação das unidades textuais de acordo com seu teor. Às unidades que se referiram a aspectos morais não relacionados aos princípios, além de condutas profissionais desejadas social mente, foi identificada a categoria "virtude".

Por fim, o código analisado, embora seja destinado a orientar a conduta ética profissional, também traz em seu conteúdo propostas prescritivas e referências a aspectos formais, como o conteúdo das propagandas e as penas previstas às infrações, que não sentenciam ou denotam qualquer conteúdo moral. Estas unidades, que explanam a respeito de aspectos técnicos, legalistas e conceituais específicos da profissão, no caso do CEO, ou das disciplinas estudadas, nos demais textos, foram classificadas na categoria "técnica".

Durante a análise do CEO, foi evidenciada ainda a necessidade de se criar subdivisões dentro das categorias autonomia e virtude. Estas foram reorganizadas de acordo com o beneficiário da conduta moral, ou seja, caso a autonomia a ser respeitada seja a do paciente, inclui-se o item na subdivi- são autonomia do paciente (autonomia P). Caso seja a autonomia do profissional, como indivíduo ou categoria profissional, referenciada, 0 item constará na subdivisão autonomia do cirurgião-dentista (autonomia CD). Respeita-se o mesmo crité rio nas subdivisões virtude $P$, ou virtude $C D$.

Atendo-se ao fato de que o objetivo principal do estudo éavaliar o CEO a partir da teoria principialista da bioética, nas unidades que expressassem aspectos técnicos, mas que também se referissem a algum princípio bioético, esta classificação sobrepunha-se à primeira. Entendendo que os conteúdos morais são mais importantes para o presente estudo do que aspectos técnicos e formais, a classificação como virtude excluiu a classificação da mesma unidade como "técnica". Estes critérios determinam que a categorização do item como "técnico" implica a não adequação a qual quer outra classificação e a ausência de referência moral na unidade.

0 "tratamento dos resultados" finaliza o estudo com o cálculo dos dados frequenciais. Da análise desses dados objetivos são derivadas as inferências que possibilitam a comparação das disciplinas entresi eas conclusões sobre o CEO e os referenciais bioéticos e deontológicos nele contemplados.

\section{Resultados}

Foi realizada a análise frequencial do CEO e dos textos de referenciais bioéticos ${ }^{1,9-13}$ e dos textos selecionados para representar a deontologia na amostra $3,6,14-17$. Os textos foram analisados e categorizados e os dados resultantes foram somados em cada grupo de textos.

Para facilitar a compreensão einterpretação do presente estudo, os dados serão apresentados ao longo do texto na seguinte ordem: inicialmente, os dados do CEO serão comentados; posteriormente, os dados da deontologia e, por último, da bioética, para possibilitar a comparação.

A análise específica do CEO compreendeu separadamente os dados pertinentes a cada uma das suas divisões: capítulos, seções, artigos, parágrafos e incisos.

Os números obtidos da análise de todas as divisões foram somados e permitem uma visualização panorâmica do quadro do CEO. Em todas as divisões do CEO, a categoria virtude foi numericamente a mais representativa ( $42 \%)$, sendo que $29,9 \%$ e $12,1 \%$ dos itens foram subclassificados, respectivamente, em virtude $C D$ evirtudeP. A categoria técnica veio a seguir com 40,2\%. A autonomia foi o princípio mais citado ( $9 \%)$, sendo que $3,6 \%$ referiam-se a autonomia CD e 5,4\% a auto- 
nomia P. Seguiram-se a justiça $(6,3 \%)$ e a nãomaleficência (5,8\%). o princípio referido com menor frequência foi a beneficência $(1,8 \%)$. Os quatro princípios somados alcançaram apenas $22,9 \%$ (Figura 1 ).

No grupo de textos deontológicos, a categoria técnica foi majoritária (38,5\%), seguida da classificação virtude (34,9\%). D os princípios bioéticos, 0 mais referenciado foi a autonomia ( $11,8 \%$ ), a justiça esteve presente em $11,2 \%$ dos parágrafos dos textos e a beneficência, em $8,6 \%$ destes. 0 menos citado, direta ou indiretamente, foi a não-maleficência, com $8,2 \%$. Os princípios, somados, atingiram 39,8\% (Figura 2).

No grupo de textos sobre bioética, a técnica também foi a categoria preponderante. No entanto, sua frequência foi menor $(32,4 \%)$, do que no grupo da deontologia (38,5\%). A segunda categoria mais citada foi referente ao princípio bioético da autonomia (26,1\%). Na categoria virtude, foram classificados $22,9 \%$ dos parágrafos dos textos bioéticos. Seguiram-sea justiça ( $11,9 \%$ ) e a beneficência $(9,1 \%)$. 0 princípio menos citado foi o da não-maleficência (7,1\%). Os quatro princípios, somados, atingiram $54,2 \%$ (Figura 3 ).
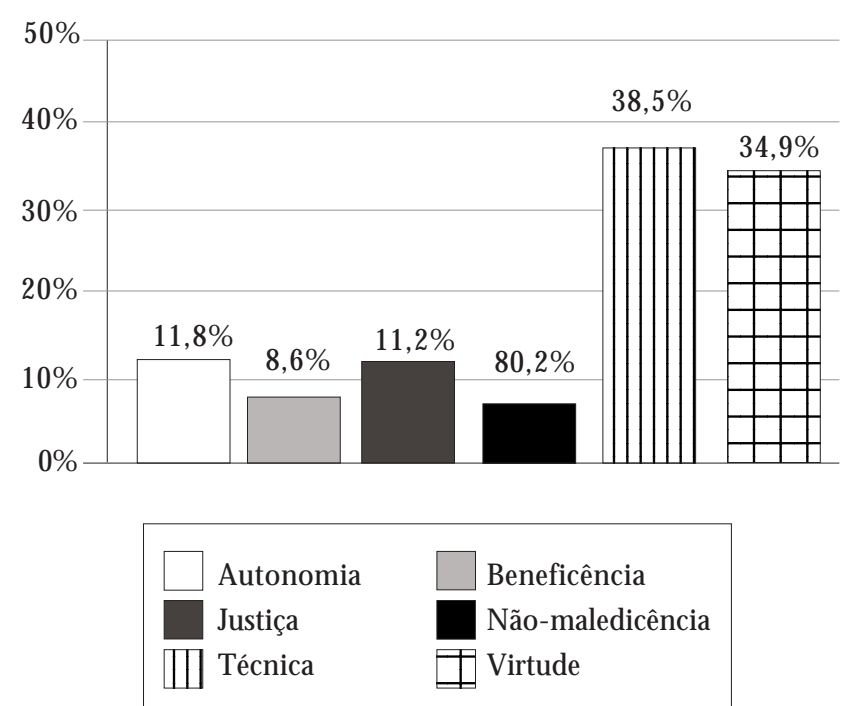

Figura 2. Classificação das unidades de contexto no grupo de textos sobre deontologia.

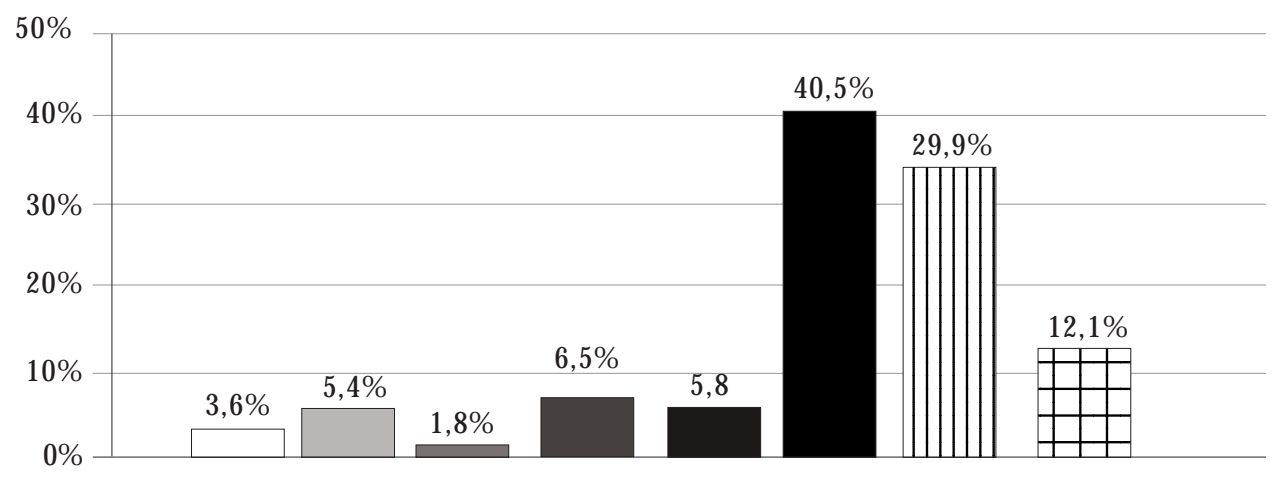

Figura 1. Classificação dos itens do Código de Ética Odontológica. 


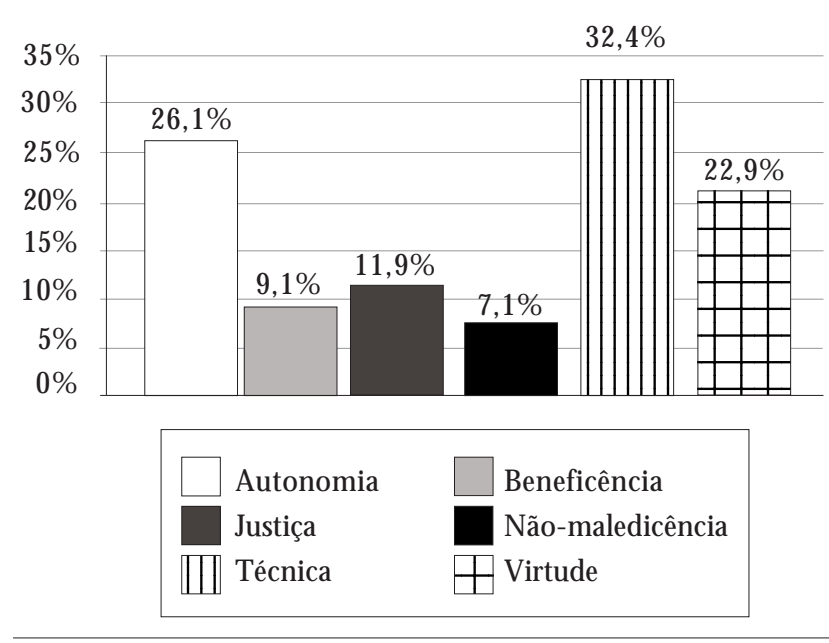

Figura 3. Classificação das unidades de contextos no grupo de textos sobre bioética.

\section{Discussão}

Um estudo desenvolvido a partir do prisma princi pialista suscita uma série de questões no contexto da bioética. Sua base conceitual, firmada com a publicação histórica de Beauchamp e Childress em $1979{ }^{18}$, com princípios pretensamente universais, foi divulgada por todo o mundo. Posteriormente, recebeu fortes críticas por não primar pela diversidade cultural. É uma vertente bi oética direcionada à relação profissional-paciente da área biomédica em geral e de cunho individualista ${ }^{19}$.

Ainda que se entenda que uma visão estritamenteprincipialista da bioética não contempletoda a pluralidade e capacidade de reflexão moral que esta disciplina oferece, o fato de ser esta a corrente considerada hegemônica e de construção epistemológica mais formal, principalmente relacionada ao exercício profissional e à relação profissional-paciente, além das questões estritamente biomédicas, permite uma verificação objetiva de sua presença no conteúdo dos textos. Daí sua adequação para detectar a influência bioética nos códigos deética.

A comparação entrea bioética ea deontologia/ ética profissional não é tema novo, sendo inegável a proximidade de alguns de seus objetos de estudo. Ambas lidam com a ética, a moral, valores, condutas e as relações humanas em geral. Diferem, no entanto, na maneira como abordam os diferentes conflitos. Enquanto a deontologia utiliza-se de códigos, prescrições e respostas determinadas, lançando mão muitas vezes de mecanis- mos punitivos àqueles profissionais que não se adéquam às regras, direcionando, portanto, ao le galismo, a bioética, em contrapartida, refere-se à legitimação das decisões morais, atuando por meio da aplicação de uma ética minimalista para mediar os conflitos, não tendo por obrigatoriedade re solvêlos². Deve sim utilizá-los como oportunidade para reflexão e desenvolvimento da capacidade humana de respeitar as moralidades diversas ecom elas conviver pacificamente.

As categorias de análise escolhidas foram de terminadas pelo referencial bioético. $\mathrm{N}$ a leitura do código, no entanto, já foi possível perceber que os princípios bioéticos não foram capazes de abarcar todos os temas abordados, tanto pelo código ser deontológico e por isso ter temáticas específicas, baseadas em virtudes e aspectos técnicos, como por entender que a teoria principialista possui limitações e realmente não abrange todas as nuances das reflexões morais.

A semelhança da apresentação gráfica dos dados obtidos da análise do CEO e dos textos deontológicos evidencia uma das primeiras inferências do presenteestudo: a proximidade encontrada entre estes no que diz respeito a sua forma e conteúdo, distanciando-se dos textos bioéticos, neste sentido. 0 estudo mostra, por exemplo, que o CEO teve o índice mais baixo de citações dos princípios bioéticos $(22,9 \%)$ comparativamente com a própria deontologiaquelhedeu origem $(39,8 \%$ ) ecom a bioética (54,2\%).

No CEO, os principais temas abordados foram enquadrados nas categorias técnica $(40,2 \%)$ e virtude ( $42 \%)$, aproximando-se do quadro apresentado nos textos deontológicos com 38,5\% e 34,9\%, respectivamente. Nos textos de conteúdo bioético, a situação foi diversa e a categoria técnica, com $32,4 \%$, foi seguida de perto pela autonomia $(26,1 \%$ ), para só então figurar a virtude (22,9\%). Destes dados, é possível inferir que os princípios têm uma maior conotação na abordagem bioética, tendo as virtudes uma importância secundária. Esta afirmação toma corpo quando comparamos o total de itens que se referem aos princípios e à virtude no CEO com $22,9 \%$ e $42 \%$, respectivamente; uma situação um pouco distintaéobservada nostextos deontológicos com 39,8\% e 34,9\%, eapresentando-sede forma inversa à bioética, 54,2\% e22,9\% .

M esmo que a representatividade dos aspectos técnicos na bioética seja grande, difere muito em conteúdo do que é encontrado na deontologia. Enquanto que, na bioética, esta categoria englobava principalmente os parágrafos referentes a terminologias e conceitos, na deontologia, o conteúdo era predominantemente prescritivo. 
A autonomia, como princípio, não é um conceito universal edentro deum mesmo idioma pode sofrer alteração de significado de acordo com o contexto. N o entanto, duas condições essenciais são unânimes para os téricos deste tema: a liberdadee a capacidade de ação intencional. Assim, é autônomo aquele que age livremente de acordo com suas próprias escolhas, tendo sua autonomia diminuída quando é controlado por outros ou impedido de agir segundo seus próprios desejos ${ }^{7}$. A autonomia possui fundamental importância para o estabelecimento decritérios nas relações depoder, como a relação profissional-paciente, por exemplo ${ }^{20}$.

Ainda que pouco citada, a autonomia ( $9 \%$ ) foi o princípio que mais esteve presente no CEO. A autonomia do paciente (autonomia $P$ ) não rece beu a importância devida na elaboração do código $(5,4 \%)$, não havendo nenhum capítulo ou artigo direcionado a esta categoria, ainda que seja mais presentedo quea categoria au tonomia CD $(3,6 \%)$. Este último fato não reflete uma maior valorização da autonomia do paciente em detrimento da autonomia do cirurgião-dentista. Reflete sim o caráter prescritivo do código quepossui noveitens sobre os direitos do profissional e os 215 restantes sobre seus deveres e normas de condutas a seguir.

A palavra autonomia não está presente no código, tampouco o significado que a teoria bioética Ihe atribui. $\mathrm{Na}$ leitura dos itens que foram classificados nesta categoria, é possível perceber que os profissionais desta área possuem uma visão segmentada deste conceito, como al go a ser conferido enão reconhecido. 0 caráter prescritivo do código não é usado na elaboração de um item que obrigue o profissional a informar o paciente sobre todas as opções terapêuticas (e não apenas as que o cirurgião-dentista realiza) disponíveis, para o caso, delegando ao pacientea livreescolha do tratamento ao qual será submetido.

Apesar de ser o princípio mais referenciado no CEO e nos dois grupos de textos, a importância dada à autonomia diverge muito nos textos estudados. O CEO e os textos deontológicos assemeIham-se muito quanto à presença desta categoria, com $9 \%$ e $11,8 \%$, respectivamente. Já os textos bioéticos ressaltam bastante este princípio em seus conteúdos, sendo que $26,1 \%$ dos parágrafos deste grupo de textos o contemplam. Estes dados reforçam não somenteuma maior val orização dos princípios bioéticos, mas também uma preocupação em legitimar a importância da autonomia como al go fundamental para a abordagem ética das mais diversas questões.

A supervalorização da autonomia, por outro lado, utilizada em detrimento dos demais princí- pios, é muito cultuada nos Estados Unidos e recebe severas críticas por levar a uma abordagem muito individualista e por vezes egoísta dos dilemas éticos ${ }^{21}$.

A beneficência, por sua vez, éum princípio que se refere a uma ação destinada a causar ben efício a outros ${ }^{7}$, sendo considerada como o fim das ações de cuidados em saúde. Por vezes, é usada como justificativa para se desconsiderar a autonomia do paciente, o que é chamado de paternalismo. Este deriva da passagem, frequentemente despercebida, do saber ao poder, anulando o paciente como ser autônomo ${ }^{22}$. As relações em queum (o paciente) se coloca sob o cuidado de outro (profissional de saúde) são muito mais suscetíveis a estetipo de conduta, pois os profissionais passam a crer que a entrega do corpo do paciente aos seus cuidados lhes outorga autoridade na escolha do tratamento.

O caráter paternalista consagrado na relação profissional-paciente, embora inicialmenteesperado, apesar deverificar-secom frequência na prática dos consultórios odontológicos, não emergiu da leitura do código. Não houve uma preponderância numérica da beneficência (1,8\%) sobre a autonomia do paciente $(5,4 \%)$ na análise do CEO. Estes dados evidenciam a transferência do foco de atenção do paciente para um caráter prescritivo, que tende à valorização do aspecto da proteção da categoria profissional odontológica em detrimento da proteção ao vulnerável desta relação, o paciente.

A beneficência foi a categoria menos citada no CEO $(1,8 \%)$ efoi a segunda menos citada nos textos deontológicos $(8,6 \%)$ e nos textos bioéticos $(9,1 \%)$. Embora este princípio seja talvez o que melhor elucide o papel do profissional de saúde diante de seu paciente ${ }^{23}$, esta categoria recebeu uma baixa valorização. Este fato pode ter duas interpretações: quando uma incipiente abordagem da beneficência se alia ao pouco respeito à autonomia, conforme o ocorrido no CEO e nos textos deontológicos, o sujeito da relação passa a ser 0 profissional; no entanto, quando a beneficência é diminuída, mas a autonomia do pacienteé respeitada, o que acontece na abordagem bioética, o paciente torna-se o centro das decisões e pleno de seus direitos.

0 princípio da não-maleficência relaciona-se com a obrigação moral denão infligir dano intencional a alguém. Está intimamente ligada à máxima hipocrática primum non nocere e compreende obrigações como não causar, impedir e eliminar os danos, fundamentais nas relações estabelecidas no campo da saúde ${ }^{7}$. $\mathrm{Na}$ análise do CEO, esta categoria emergiu do discurso, porém de forma muito tímida. Esta pouca frequência pode estar relacionada ao 
fato de ser um princípio que contém certa obviedade em si, já que não se espera de um profissional de saúde que ele, durante sua prática clínica, atue com o propósito de causar dano ao seu paciente.

No CEO, a categoria não-maleficência $(5,8 \%)$ foi relacionada a fatores como a recomendação do não uso de materiais ou métodos ainda não consagrados pela ciência ou a não extrapolação de sua atuação profissional ${ }^{4}$, assemelhando-semuito com a limitação do tema apresentado nos textos deontológicos (8,2\%), expressando mais uma postura legalista do que uma reflexão ética. N os textos bioéticos $(7,1 \%)$, apesar da frequência ser semelhante às anteriores, o sentido usado para este princípio é muito mais amplo e abrange aspectos culturais e ambientais e suas implicações na humanidade, como é percebido na Declaração Universal sobre Bioética e Direitos H umanos ${ }^{13}$.

A justiça é, juntamentecom a não-mal eficência, um princípio de base coletiva, segundo Gracia24. Esta valoração é pertinente, pois guarda uma relação muito íntima com o acesso a cuidados de saúde, sendo justo todo o tratamento equitativo eapropriado, levando em consideração aquilo o que é devido às pessoas? ${ }^{7}$. A justiça não é apenas uma distribuição igualitária dos recursos, compreende a igual consideração dos interesses e a não discriminação de qualquer natureza como seus alicerces.

No CEO, o contexto de justiça (6,3\%) é aplicado principalmente nositens que abordam o acesso a tratamento odontológico e a não discriminação dos pacientes. A pouca representatividadena amostra caracteriza a percepção que o cirurgião-dentista possui em relação à coletividade e a diversidade. Preocupado com questões, por ele julgadas mais importantes, não dá o devido valor à questão da diversidade e à adequação necessária de sua atividadeao meio sociocultural no qual exerce a profissão. Os referenciais deontológicos $(11,2 \%)$ ofere cem uma visão legalista da temática da justiça, enquanto nos textos bioéticos (11,9\%) o sentido que se dá é mais amplo e voltado à coletividade, com temas como a marginalização e pobreza, distribuição dos benefícios das descobertas científicas, entre outros ${ }^{13}$.

A soma dositens referentes às categorias técnica e virtude no CEO totaliza $82,2 \%$ de seu conteúdo, evidenciando a supervalorização do referencial epistemológico deontológico em detrimento do bioético, valorizando as virtudes, principalmente aquelas relacionadas ao próprio profissional, e aspectos técnicos, em detrimento de uma reflexão embasada nos referenciais bioéticos. A soma das mesmas categorias nos textos estudados e referentes à deontologia atingiu $73,4 \%$, enquanto na bio- ética chegou a apenas $55,3 \%$, mostrando coerência com os demais dados aferidos pela pesquisa.

A valorização das virtudes relacionadas ao cirurgião-dentista e à categoria profissional odontológica evidencia que o código está voltado para o lado mais forte da relação. Neste sentido, a presente pesquisa diverge diametralmente do estudo desenvolvido por Lucato e Ramos ${ }^{25}$ que, por meio de metodologia pouco elucidativa, concluiu que a atual versão do Código de Ética O dontológica, diferentemente das versões anteriores, coloca o paciente como o centro do exercício da atenção odontológica ${ }^{25}$. 0 estudo aqui apresentado, ao contrário, demonstra que o CEO, na sua versão atual, é centrado essencialmentena figura do profissional, cabendo ao paciente um papel coadjuvante como objeto de sua prática.

\section{Conclusão}

A odontologia éuma ciência com constantes avanços tecnológicos que fertilizam seus conhecimentos teóricos e refinam sua eficiência terapêutica. A pesar de seus aparatos técnicos sempre se atualizarem como resposta à dinâmica ciência moderna, as reflexões éticas evidenciadas no código de ética profissional, em vigência no país, não acompanharam as transformações morais constatadas na sociedade brasileira contemporânea.

$\mathrm{N}$ a prática odontológica, são frequentes as atitudes que demonstram desrespeito aos princípios bioéticos, por exemplo, quando o paciente não é adequadamente informado ou não possui o direito de escolher, após os devidos esclarecimentos, 0 tratamento ao qual será submetido9. O CEO, de conteúdo basicamenteprescritivo e formado principalmente de referências a aspectos técnicos, vazios de significado moral, apóia-se em prescrições previamente estabelecidas para resolver os conflitos éticos, o que pode dificultar a orientação de condutas éticas diante da diversidade moral que predomina na atualidade.

A pesar de já na primeira versão do CEO o paciente ser referido como "a razão e o objetivo de toda a ciência odontológica", a leitura do código atual leva à conclusão oposta. O CEO configurase como um instrumento de proteção dos profissionais, criado por estes para estes, com uma postura muito mais corporativista do que se deseja admitir.

Divergindo de estudo anterior ${ }^{25}$, que conclui que o código éum instrumento de novo olhar sobre o ser humano, que ressalta a importância da humanização no atendimento e valoriza a aliança 
entre o progresso técnico-científico e as relações assistenciais, os resultados da presente pesquisa mostram que o CEO sustenta-se em aspectos corporativistas elegal istas, com predominância de itens técnicos e legais, ena valorização das virtudes relacionadas com o próprio profissional em detrimento dos princípios da bioética. N este aspecto, a bioética pode proporcionar uma contribuição significativa. Com seu estatuto epistemológico maisflexível e menos prescritivo, oferece a possibilidade de um conteúdo mais adequado à contemporaneidade das sociedades plurais pós-modernas, como a brasileira, onde se dá o exercício dos profissionais regidos pelo código estudado na presente pesquisa.

\section{Colaboradores}

M Pyrrho participou da revisão de literatura, elaboração do projeto, análise de conteúdo dos textos, tabulação e interpretação dos dados e elaborou a redação final do artigo. M M Prado participou da revisão de literatura, seleção dos textos e revisão do texto final. J Cordón participou da elaboração do projeto ecolaborou na revisão do texto final. V Garrafa atuou como orientador em todas as fases do estudo, participou da revisão de literatura, elaboração do projeto, análise de conteúdo dos textos, tabulação e interpretação dos dados, elaboração da redação do artigo e revisão final do texto.

\section{Referências}

1. Garrafa V. Bioética e ética profissional: esclarecendo a questão. M edicina - Conselho Federal 1998; 97:28.

2. Garrafa V. Multi-inter-transdisciplinaridade, complexidade e totalidade. In: Garrafa V, Kottow M, Saada A, organizadores. Bases conceituais da bioética - enfoque latino-americano. São Paulo: Editora Gaia/ UNESC0; 2006. p. 73-91.

3. $M \operatorname{arcos} B$. Regulamentação da profissão e código de ética profissional. In: M arcos B. Ética e profissionais de saúde. São Paulo: Livraria Editora Santos; 1999. p. 185-201.

4. Resolução CFO-42 /2003. Revoga o Código de Ética Odontológica aprovado pela Resolução CFO-179/91 e aprova outro em substituição. Conselho Federal de Odontologia 2003; 20 maio.

5. Resolução CFO-71/2006. Texto do Capítulo XIV alterado através da Resolução CFO-71, de 06 de junho de 2006, aprovada na CCIX Reunião Ordinária, de 25 de maio de 2006, que referendou as decisões da CCVII Reunião Ordinária do Plenário do Conselho Federal de Odontologia - Assembléia Conjunta com os Conselhos Regionais de Odontologia, em Recife, nos dias 06 e 07 de abril de 2006. Conselho Federal de 0 dontologia 2006, 06 e $07 \mathrm{abr}$.

6. Ramos DLP. Alguns comentários sobre ética profissional odontológica. In: Silva MS, organizador. Compêndio de odontologia legal. Rio de Janeiro: Medsi; 1997. p. 51-58.

7. Beauchamp T, Childress J. Principles of biomedical ethics, $5^{\text {th }}$ ed. New York: Oxford University Press; 2001.

8. Bardin L. Análise de conteúdo. Lisboa: Edições 70; 2000.

9. Garbin CA, Mariano RQ, Machado TP, Garbin AJI. Estudo bioético das relações humanas no tratamento odontológico. Rev. Univ. M etodista de Piracicaba 2002; 14(1):54-59.

10. Garrafa V. Bioética e odontologia. In: Krieger L, organizador. Promoção de saúde bucal. 3a ed. São Paulo: Artes M édicas; 2003.

11. Garrafa V, Bugarin Jr JG, Prado M M. Bioética e odontologia. In: Vieira TR, organizador. Bioética e profissões. Petrópolis:Vozes; 2005. p. 85-100.

12. Gonçalves ER, Verdi MIM. A vulnerabilidade e o paciente da clínica odontológica de ensino. Rev. Bras. de Bioética 2005; 1(2):195-205.
13. UNESCO. Declaração Universal sobre Bioética e Direitos Humanos 2005. [acessado 2006 out 10]. Disponível em: http://www.bioetica.catedraunesco.unb.br

14. $M \operatorname{arcos} B$. Por que as normas? In: M arcos B. Ética e profissionais de saúde. São Paulo: Livraria Editora Santos; 1999. p. 169-177.

15. Maruyama NT, Ramos DL. A discriminação no atendimento odontológico a pacientes com HIV+. 0 M undo da Saúde 1996; 4:149-152.

16. Ramos DLP, Trindade OM. Ética na pesquisa odontológica com seres humanos. In: Silva M.S, organizador. Compêndio de odontologia legal. Rio de Janeiro: Medsi; 1997. p. 73-90.

17. Puppin AAC, Paiano GA, Piazza JL, Torriani MA. Ético versus legal - Implicações na prática clínica. Rev. ABO Nacional 2000; 8(1):38-41.

18. Beauchamp T, Childress J. Principles of biomedical ethics. $1^{\text {st }}$ ed. New York: Oxford University Press; 1979.

19. Garrafa V, Kottow M, Saada A, organizadores. Bases conceituais da bioética - enfoque latino-americano. São Paulo: Editora Gaia/ UNESCO; 2006.

20. Drumond JGF. A formação ética do médico e a perspectiva profissional. M edicina - Conselho Federal 2001; 128:8-9.

21. Selleti J, Garrafa V. As raízes cristãs da autonomia. Petrópolis: Vozes; 2005.

22. Silva FL. Beneficência e paternalismo. Medicina Conselho Federal 1997; 87:8-9.

23. Pinheiro ALB. Onde está nossa responsabilidade? É ético recusar atendimento ao paciente soropositivo para o HIV ou com AIDS? Rev. Assoc. Paul. Cirurg. Dent. 1998; 1(6):24-25.

24. Gracia D. La bioética médica. In: Organización Panamericana de la Salud/OM S. Bioetica: temas y perspectivas 1991; 527:3-7.

25. Lucato MC, Ramos DLP. A humanização das relações assistenciais no Código de Ética Odontológica. 0 M undo da Saúde 2006; 30(3):417-424

Artigo apresentado em 02/03/2007

Aprovado em 24/08/2007

Versão final apresentada em 18/10/2007 